\title{
Anti-cancer effects of 2-oxoquinoline derivatives on the HCT116 and LoVo human colon cancer cell lines
}

\author{
FENG-QI FANG ${ }^{1 *}$, HUI-SHU GUO ${ }^{2 *}$, JIE ZHANG $^{1}$, LI-YING BAN ${ }^{1}$, JI-WEI LIU ${ }^{1}$ and PEI-YAO YU ${ }^{1}$ \\ ${ }^{1}$ Department of Oncology; ${ }^{2}$ Central Laboratory, The First Affiliated Hospital of Dalian Medical University, \\ Dalian, Liaoning 116011, P.R. China
}

Received October 29, 2014; Accepted August 8, 2015

DOI: $10.3892 / \mathrm{mmr} .2015 .4451$

\begin{abstract}
The present study demonstrated the anti-tumor effects of the quinoline derivative [5-(3-chloro-oxo-4-phenyl -cyclobutyl)-quinoli-8-yl-oxy] acetic acid hydrazide (CQAH) against colorectal carcinoma. Substantial apoptotic effects of CQAH on HCT116 and LoVo human colon cancer cell lines were observed. Apoptosis was identified based on cell morphological characteristics, including cell shrinkage and chromatin condensation as well as Annexin V/propidium iodide double staining followed by flow cytometric analysis and detection of apoptosis-associated proteins by western blot analysis. CQAH induced caspase-3 and PARP cleavage, reduced the expression of the anti-apoptotic proteins myeloid cell leukemia-1 and B-cell lymphoma (Bcl) extra large protein and elevated the expression of the pro-apoptotic protein $\mathrm{Bcl}-2$ homologous antagonist killer. In addition, pharmacological inhibition of c-Jun N-terminal kinase (JNK), but not extracellular signal-regulated kinase or p38, significantly reduced CQAH-mediated cell death as well as cleavage of caspase-3 and PARP. Co-treatment of CQAH with the commercial chemotherapeutics 5-fluorouracil and camptothecin-11 significantly improved their efficacies. Comparison of the apoptotic effects of CQAH with those of two illustrated structure-activity associations for this compound type, indicating that substitution at position- 4 of the azetidine phenyl ring is pivotal for inducing apoptosis. In conclusion, the results of the present study indicated CQAH and its analogues are potent candidate drugs for the treatment of colon carcinoma.
\end{abstract}

Correspondence to: Dr Pei-Yao Yu, Department of Oncology, The First Affiliated Hospital of Dalian Medical University, 222 Zhongshan Road, Xigang, Dalian, Liaoning 116011, P.R. China E-mail: peiyaoy@gmail.com

*Contributed equally

Key words: 2-oxoquinoline, apoptosis, colon cancer

\section{Introduction}

Cancer is one of the greatest challenges in the clinical field worldwide and its occurrence is increasing in developed as well as in developing countries. In the United States, colorectal cancer is considered to be the second-largest cause of cancer-associated mortality $(1,2)$. In spite of the fact that the genetics of colon cancer have been studied in depth (3), current therapies are not able to effectively treat colorectal cancer $(4,5)$.

Although colorectal cancer can be cured at early stages, patients frequently present with metastases at the time-point of the occurrence of symptoms and diagnosis, leading to a high mortality rate (6). Hence, research efforts focus on developing novel and more potent preventive and screening methods for colon cancer (7). Numerous studies have shown that the mortality rate arising from colorectal cancer decreased to $40-50 \%$ in patients with colorectal cancer taking non-steroidal anti-inflammatory drugs and aspirin (8-13), clearly demonstrating the chemopreventive effects of these drugs. Other studies reported that sunlindac is a potent drug causing a regression of the adenoma count and size in patients with adenomatous polyposis (14-17). The primary method of colon cancer treatment is surgery. 5-fluoruracil (5-FU), camptothecin-11 (CPT-11; irinotecan) and oxaliplatin are the most common chemotherapeutic drugs used to destroy cancer cells after tumor resection $(18,19)$. Combinatorial treatment of drug administration and surgery has enhanced therapeutic efficacy as compared with that of monotherapy $(20,21)$. Besides from irradiation and surgical treatments, chemotherapy remains one of the primary choices for cancer treatment (22).

Quinoline moieties and their oxo-derivatives have gained substantial interest due to their occurrence in a wide range of natural products and bio-active compounds (23). 3 -substituted quinoline-2-one is a key moiety present in a variety of compounds with anti-cancer properties, and quinoline-2-one-based compounds were found to be effective and promising lead structures for kinase inhibition (24).

Azetidinones are part of the structural skeleton of several antibiotics and are widely known to exhibit potent biological activities (25). Synthesis of azetidinone derivatives has provided variety of novel compounds with applications including anti-bacterial, antimicrobial, anti-convulsant, anti-inflammatory and anti-tuberculosis properties (26-30). They can 
also act as enzyme inhibitors and exert effects on the central nervous system (31). Another class of heterocyclic compound, 8-hydroxy quinolines, has been demonstrated to have valuable biological activities, with derivatives being used as effective human immunodeficiency virus-1 intergrase inhibitors $(32,33)$, as antimicrobial compounds or as herbicides (34-36). Quinoline-based synthetic azetidinone derivatives have also shown potential anti-microbial properties $(37,38)$. Based on the abovementioned findings, the present study investigated the anti-cancer effects of compounds containing azetidine and the quinoline-2-one skeleton combined in one molecule. Madhu et al (39) have previously synthesized [5-(3-chloro-oxo -4-phenyl-cyclobutyl)-quinoli-8-yl-oxy] acetic acid hydrazide (CQAH), which showed efficacy against a range of bacteria and fungi. The present study explored the effects of CQAH as well as two if its derivatives, CQAH-1 and -2, bearing a methyl- or nitro-substitution, respectively, at position- 4 of the azetidine phenyl ring (Fig. 1), on colorectal cancer in order to assess their potential for use as novel chemotherapeutic drugs.

\section{Materials and methods}

Compounds and reagents. CQAH and its derivatives were prepared according to the procedure of a previous study (39). The identity of the compounds was confirmed by infrared (IR) spectroscopy and nuclear magnetic resonance (NMR). The spectroscopical data, with assignments as singulet (s), multiplet (m) and duplet (d) were as follows:

2-((5-(3-chloro-2-oxo-4-phenylazetidin-1-yl) quinolin-8-yl)oxy)acetohydrazide $(C Q A H)$. IR $(\mathrm{KBr})$ in $\mathrm{cm}^{-1}$ : $674(-\mathrm{Cl}), 1,625(-\mathrm{C}=\mathrm{N}), 1,685(-\mathrm{C}=\mathrm{O}), 3,210(-\mathrm{NH}), 3,410$ $\left(-\mathrm{NH}_{2}\right), 3,486 .{ }^{1} \mathrm{HNMR}\left[300 \mathrm{MHz},\left(\mathrm{CD}_{3}\right)_{2} \mathrm{SO}\right.$, tetramethylsilane (TMS)]: $\delta=2.09\left(\mathrm{~s}, 2 \mathrm{H},-\mathrm{NH}_{2}\right), 4.7\left(\mathrm{~s}, 2 \mathrm{H},-\mathrm{O}-\mathrm{CH}_{2}\right), 5.12$ (d, 1H, - CH of azetidin attached to phenyl), $5.41(\mathrm{~d}, 1 \mathrm{H},-\mathrm{CH}$ of azetidin attached to $-\mathrm{Cl}), 6.55(\mathrm{~d}, 1 \mathrm{H},-\mathrm{CH}), 6.78(\mathrm{~d}, 1 \mathrm{H}$, $-\mathrm{CH})$, 7.1-7.2 (m, 5H of $\left.\mathrm{C}_{6} \mathrm{H}_{5}\right), 7.8-8.8(\mathrm{~m}, 3 \mathrm{H}$ of quinoline ring), 10.08 (s, $1 \mathrm{H},-\mathrm{NH}) .{ }^{13} \mathrm{C} \mathrm{NMR}\left(75 \mathrm{MHz}, \mathrm{CDCl}_{3}, \mathrm{TMS}\right)$ $\delta=60(\mathrm{C}-\mathrm{Cl}), 63(\mathrm{~N}-\mathrm{CH}-\mathrm{Ar}), 68\left(\mathrm{O}-\mathrm{CH}_{2}\right), 108,115,119,121$, 127 (Ar-C), 128, 129, 138, 134, 141, 147, 150, $161(\mathrm{~N}-\mathrm{C}=\mathrm{O})$, $167(-\mathrm{CO}-\mathrm{N})$.

2-(5-(3-chloro-2-oxo-4-p-tolylazetidin-1-yl)

quinolin-8-yloxy)acetohydrazide (CQAH-1). IR (KBr) in $\mathrm{cm}^{-1}$ : $678(-\mathrm{Cl}), 1,620(-\mathrm{C}=\mathrm{N}), 1,684(-\mathrm{C}=\mathrm{O}), 3,208(-\mathrm{NH}), 3,410$ $\left(-\mathrm{NH}_{2}\right), 3,494 .{ }^{1} \mathrm{HNMR}\left[300 \mathrm{MHZ},\left(\mathrm{CD}_{3}\right)_{2} \mathrm{SO}, \mathrm{TMS}\right]: \delta=2.10$ (s, $\left.2 \mathrm{H},-\mathrm{NH}_{2}\right), 2.30$ (s, 3H, Ar- $\left.\mathrm{CH}_{3}\right), 4.73$ (s, 2H, -O-CH $\left.{ }_{2}\right), 5.14$ (d, $1 \mathrm{H}$ azetidin- $\mathrm{CH}$ attached to phenyl), 5.45 (d, $1 \mathrm{H}$, azetidin- $\mathrm{CH}$ attached to $\mathrm{Cl}), 6.3(\mathrm{~d}, 1 \mathrm{H},-\mathrm{CH}), 6.4(\mathrm{~d}, 1 \mathrm{H}$, $-\mathrm{CH}), 7.0\left(\mathrm{~m}, 4 \mathrm{H}\right.$ of $\left.\mathrm{C}_{6} \mathrm{H}_{4}\right), 8-8.7$ ( $\mathrm{m}, 3 \mathrm{H}$ of quinoline ring), 10.08 (s, 1H, -NH). ${ }^{13} \mathrm{C}$ NMR (75 MHz, $\left.\mathrm{CDCl}_{3}, \mathrm{TMS}\right) \delta=25$ $\left(\mathrm{Ar}-\mathrm{CH}_{3}\right), 62(\mathrm{C}-\mathrm{Cl}), 65(\mathrm{~N}-\mathrm{CH}-\mathrm{Ar}), 67\left(\mathrm{O}-\mathrm{CH}_{2}\right), 114,117,123$, 127, 128, 130, 134 (Ar-C), 135, 137, 139, 147, 150, 162 $(\mathrm{N}-\mathrm{C}=\mathrm{O}), 167,168(-\mathrm{CO}-\mathrm{N})$.

2-((5-(3-chloro-2-(4-nitrophenyl)-4-oxoazetidin-1-yl) quinolin-8-yl)oxy) acetohydrazide (CQAH-2). IR (KBr) in $\mathrm{cm}^{-1}: 675(-\mathrm{Cl}), 1,614(-\mathrm{C}=\mathrm{N}), 1,680(-\mathrm{C}=\mathrm{O}), 3,208(-\mathrm{NH})$, $3,412\left(-\mathrm{NH}_{2}\right), 3,494 .{ }^{1} \mathrm{H}$ NMR [300 MHZ, $\left.\left(\mathrm{CD}_{3}\right)_{2} \mathrm{SO}, \mathrm{TMS}\right]$ : $\delta=2.10\left(\mathrm{~s}, 2 \mathrm{H},-\mathrm{NH}_{2}\right), 4.80\left(\mathrm{~s}, 2 \mathrm{H},-\mathrm{O}-\mathrm{CH}_{2}\right), 5.13$ (d, $1 \mathrm{H},-\mathrm{CH}$ of azetidin attached to phenyl ring), $5.46(\mathrm{~d}, 1 \mathrm{H},-\mathrm{CH}$ of azetidin attached to $-\mathrm{Cl}), 6.54(\mathrm{~d}, 1 \mathrm{H},-\mathrm{CH}), 6.74(\mathrm{~d}, 1 \mathrm{H},-\mathrm{CH})$, 7.0-8.0 (m, $4 \mathrm{H}$ of $\mathrm{C}_{6} \mathrm{H}_{4}$ ), 7.3-8.8 (m, $3 \mathrm{H}$ of quinoline ring),
10.10 (s, 1H, -NH). ${ }^{13} \mathrm{C}$ NMR (75 MHz, $\left.\mathrm{CDCl}_{3}, \mathrm{TMS}\right) \delta=62$ (C-Cl), 65 (N-CH-Ar), $67\left(\mathrm{O}-\mathrm{CH}_{2}\right), 106,117,120,122,127$, 129, 134, 138, 147 (Ar-C), 151, 153, $162(\mathrm{~N}-\mathrm{C}=\mathrm{O}), 167$ (-CO-N).

All chemicals used in the present study were purchased from Sigma-Aldrich (St. Louis, MO, USA). Diphenylene iodonium (DPI), MTT and $N$-acetyl-L-cysteine (NAC) were obtained from Sigma-Aldrich. Antibodies against c-Jun N-terminal kinase (JNK; cat no. 8528; 1:5,000; rabbit polyclonal $\mathrm{IgG}, 1 \mathrm{~h}$ at $25^{\circ} \mathrm{C}$ ) and phosphorylated (p)-JNK (cat no. 4668; 1:2,000; rabbit polyclonal $\mathrm{IgG}, 1 \mathrm{~h}$ at $25^{\circ} \mathrm{C}$ ) were obtained from Cell Signaling Technology, Inc. (Beverly, MA, USA). Antibodies against B-cell lymphoma (Bcl) extra-large protein (Bcl-XL; cat no. GTX100632; 1:3,000; rabbit polyclonal $\mathrm{IgG}, 1 \mathrm{~h}$ at $\left.25^{\circ} \mathrm{C}\right)$, Bcl-2 homologous antagonist killer (Bak; cat. no. GTX100063; 1:3,000; rabbit polyclonal IgG, $1 \mathrm{~h}$ at $\left.25^{\circ} \mathrm{C}\right)$, poly(adenosine diphosphate ribose) polymerase (PARP; cat no. GTX100573; 1:3,000; rabbit polyclonal IgG, $1 \mathrm{~h}$ at $25^{\circ} \mathrm{C}$ ), caspase-3 (cat. no. GTX110543; 1:3,000; rabbit polyclonal $\mathrm{IgG}, 1 \mathrm{~h}$ at $25^{\circ} \mathrm{C}$ ), myeloid cell leukemia 1 (Mcl-1; cat. no. GTX102026; 1:1,000; rabbit polyclonal $\mathrm{IgG}, 1 \mathrm{~h}$ at $25^{\circ} \mathrm{C}$ ) and $\alpha$-tubulin (cat. no. GTX112141; 1:10,000; rabbit polyclonal $\mathrm{IgG}, 1 \mathrm{~h}$ at $25^{\circ} \mathrm{C}$ ) were purchased from Gene Tex (San Antonio, TX, USA). Mitogen-activated protein kinase (MAPK) inhibitors, including extracellular signal-regulated kinase (ERK) inhibitor PD98059, p38 inhibitor SB203580 and JNK inhibitor SP600125 were obtained from Merck Millipore (Billerica, MA, USA).

Cell culture and MTT assay. The HCT116 and LoVo human colorectal cancer cell lines were purchased from the American type culture collection (Manassas, VA, USA). These cells were maintained in Dulbecco's modified Eagle's medium (Sigma-Aldrich) supplemented with 5\% heat-activated fetal bovine serum (FBS), penicillin-streptomycin (100 U) and sodium pyruvate $(1 \mathrm{mM})$ in a humidified incubator with $5 \%$ $\mathrm{CO}_{2}$ at $37^{\circ} \mathrm{C}$.

For the MTT assay, HCT116 and LoVo cells seeded in 24-well plates at a density of $1 \times 10^{5}$ per well in growth medium (Sigma-Aldrich). Subsequent to the cells being re-fed with growth medium, they were incubated with various concentrations of CQAH $(0-20 \mu \mathrm{M})$ for 24 or $48 \mathrm{~h}$. The growth medium was fully removed and the cells were incubated with MTT solution $(50 \mu \mathrm{g} / \mathrm{ml})$ for $2 \mathrm{~h}$. The obtained formazan crystals were dissolved in isopropanol and the absorbance was recorded at a wavelength of $560 \mathrm{~nm}$ using an ELISA reader (SpectraMax 190; Molecular Devices Inc., Sunnyvale, CA, USA). The cell viability was determined as a percentage of the control.

In order to determine the role of the MAPK pathway in drug-induced apoptosis, cells were pretreated with inhibitors of ERK (PD98059; 10 and $20 \mu \mathrm{M}$ ); JNK (SP600125; 10 and $20 \mu \mathrm{M})$ or p38 (SB203580; 10 and $20 \mu \mathrm{M})$. CQAH $(10 \mu \mathrm{M})$ treatment was performed for $48 \mathrm{~h}$ and the viability of the cells was measured using an MTT assay.

The cells were treated with the antioxidant agents NAC (glutathione activator) and DPI (NAPDH inhibitor) to determine their role in drug-induced cell death. Cells were pretreated with inhibitors of glutathione (NAC; 5 and $10 \mu \mathrm{M}$ ) or NADPH (DPI; 5 and $10 \mu \mathrm{M})$. CQAH $(10 \mu \mathrm{M})$ was added and cells were incubated for $48 \mathrm{~h}$. The viability of the cells was assessed using an MTT assay. 

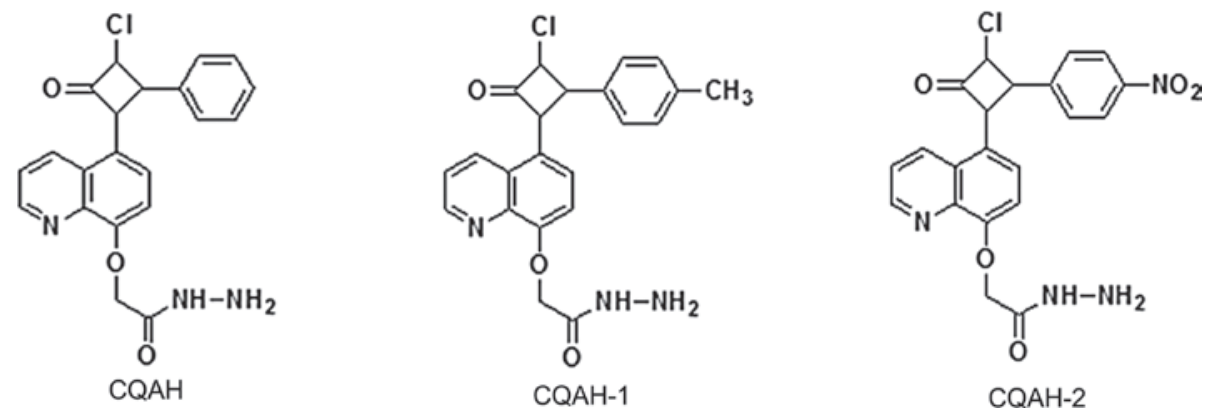

Figure 1. Chemical structures of the 2-oxoquinolines CQHA, CQAH-1 and CQAH-2.

Assessment of apoptosis. Cells at a density of $1 \times 10^{5}$ per well were seeded into wells containing glass slips and treated with CQAH $(10 \mu \mathrm{M})$ for $24 \mathrm{~h}$. The slips were fixed with methanol for $10 \mathrm{~min}$ and treated with DAPI for $30 \mathrm{~min}$. Slides were mounted with mounting medium (Santa Cruz Biotechnology, Inc., Dallas, TX, USA). The percentage of apoptotic nuclei was determined by counting condensed and bright nuclei compared with the total number of cells.

In another experiment, the cells were pretreated with inhibitors of caspase-3 (Z-DEVD-FMK; 50 and $100 \mu \mathrm{M}$ ) or caspase-9 (Z-LEHD-FMK; 50 and $100 \mu \mathrm{M}$ ) to inhibit the action of apoptosis-associated enzymes. CQAH $(10 \mu \mathrm{M})$ was then added for $48 \mathrm{~h}$. The cell viability was measured using an MTT assay.

Annexin V-propidium iodide (PI) staining. An Annexin-V-fluorescein isothiocyanate (FITC)/double staining kit (BD Biosciences, Franklin Lakes, NJ, USA) was used to quantify the apoptosis of CQAH-treated HCT116 and LoVo cells. In brief, HCT116 and LoVo cells at a density of $1 \times 10^{5}$ per well were seeded in 24-well plates and then treated with CQAH at various concentrations $(0-20 \mu \mathrm{M})$ for $24 \mathrm{~h}$. The cells were then trypsinized, treated with binding buffer and Annexin-FITC and PI were added, followed by incubation for $15 \mathrm{~min}$ in the dark according to the manufacturer's instructions of the apoptosis kit. The cells were analyzed using a FACSCalibur flow cytometer (BD Biosciences).

Western blot analysis. For western blot analysis, HCT116 and LoVo cells were washed two times using ice-cold phosphate-buffered saline (PBS) and then extracted in radioimmunoprecipitation assay buffer containing Tris- $\mathrm{HCl}$ (50 mM, pH 7.4), 1\% nonidet P-40, $\mathrm{NaCl}(150 \mathrm{mM})$, ethylene glycol tetraacetic acid (1 mM), sodium deoxycholate $(0.025 \%)$, sodium orthovanadate $(1 \mathrm{mM})$, phenylmethyl sulfonylfluoride (1 $\mathrm{mM})$, and $\mathrm{NaF}(1 \mathrm{mM})$. Cell extracts were examined with the Bio-Rad protein assay kit (Bio-Rad Laboratories, Inc. Hercules, CA, USA) in order to quantify the protein concentration using bovine serum albumin (BSA) as a standard. The ELISA reader was used to measure the absorbance at a wavelength of $595 \mathrm{~nm}$. Equal quantities of protein $(50 \mu \mathrm{g})$ separated by $8 \%$ SDS-PAGE and then transferred onto immobilon polyvinylidene difluoride membranes (Merck-Millipore). 1\% BSA was used to block the membranes at room temperature, and membranes were subsequently incubated with specific primary antibodies overnight. Membranes were washed three times in
PBS containing Tween 20, followed by incubation with horseradish peroxidase-conjugated secondary antibody for $1 \mathrm{~h}$. The protein expression was visualized using an enhanced chemiluminescence assay kit (cat. no. WBKLS0500; Merck-Millipore) by ImageQuant LAS4000 (GE Healthcare Bio-Sciences, Pittsburgh, PA, USA).

In order to determine the role of the MAPK pathway in drug-induced apoptosis, cells were pretreated with inhibitors of ERK (PD98059; 10 and $20 \mu \mathrm{M}$ ); JNK (SP600125; 10 and $20 \mu \mathrm{M})$ or p38 (SB203580; 10 and $20 \mu \mathrm{M})$. CQAH $(10 \mu \mathrm{M})$ treatment was performed for $48 \mathrm{~h}$. The protein expression of MAPK-associated proteins was assessed using western blot analysis.

In order to determine the role of antioxidants in drug-induced cell death, cells were treated with NAC $(10 \mu \mathrm{M})$ and DPI $(5 \mu \mathrm{M})$ in the presence of CQAH $(10 \mu \mathrm{M})$ for $24 \mathrm{~h}$, and the protein expression of PARP and caspase- 3 was analyzed using western blotting.

Transient transfection. HCT116 and LoVo cells were first seeded in 6-cm dishes and transfection was performed using dominant-negative JNK (DN-JNK) or pcDNA3 with PolyJect reagent according to the manufacturer's instructions (SignaGen Laboratories, Gaithersburg, MD, USA). After 24 h of transfection, cells were trypsinized, seeded in a 24-well plate and then treated with CQAH for $48 \mathrm{~h}$.

Statistical analysis. All experimental data are from three independent experiments and values are expressed as the mean \pm standard error. Statistical analysis was conducted with GraphPad Prism, version 5.0 (GraphPad Software, Inc., La Jolla, CA, USA). Differences between groups were assayed using Student's t-test for each paired experiment. $\mathrm{P}<0.05$ was considered to indicate a statistically significant difference between values.

\section{Results}

CQAH decreases the viability of HCT116 and LoVo human colorectal cancer cells by inducing apoptosis. CQAH and its analogues (Fig. 1) have been previously shown to exhibit anti-bacterial activity against Escherichia coli, Bacillus cereus, Staphylococcus aureus and Pseudomonas aeruginosa (39); however, their effects on cancer have not been elucidated, to the best of our knowledge. In order to assess the effects of CQAH on colon cancer, the HCT116 and LoVo cell lines were 
A

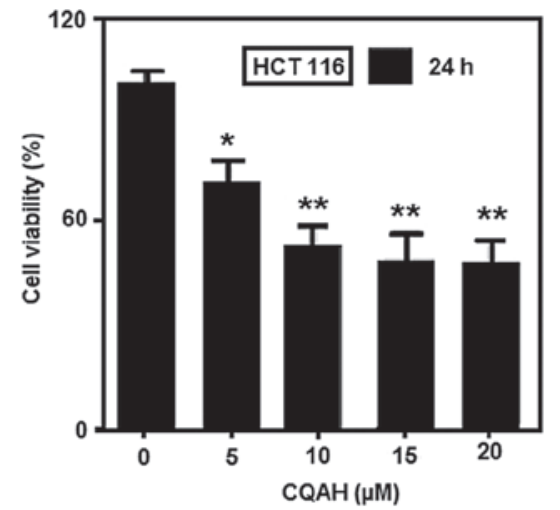

B

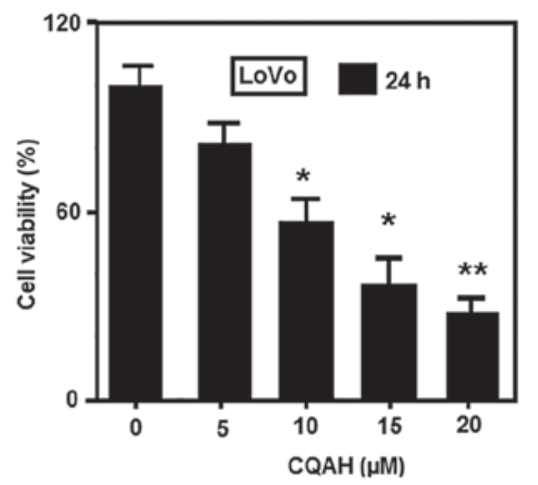

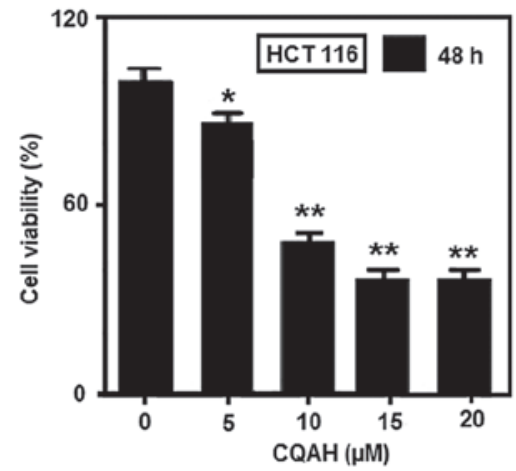

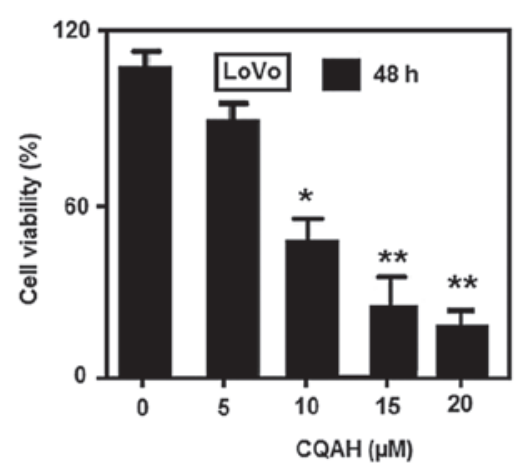

C

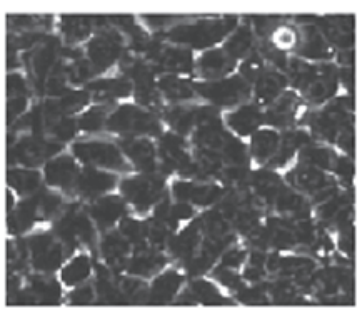

E CQAH 0

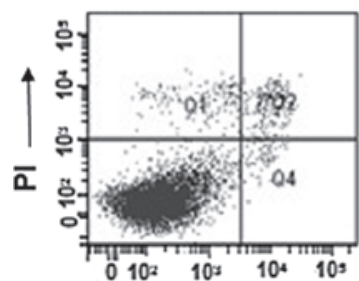

CQAH 5

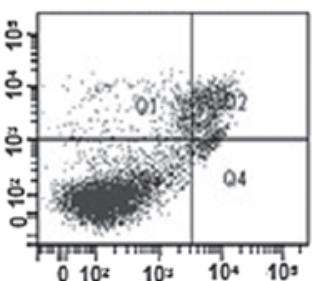

D
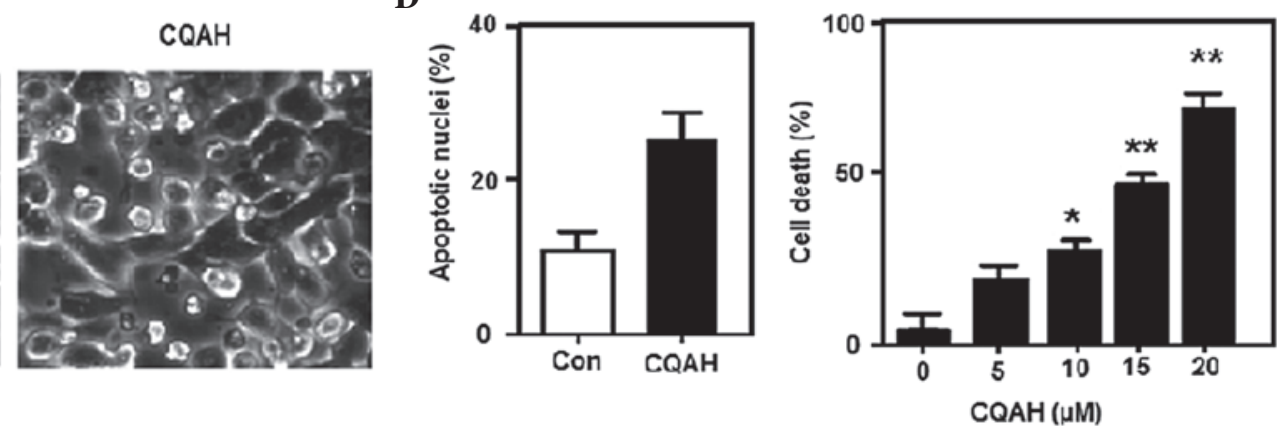

Con CQAH
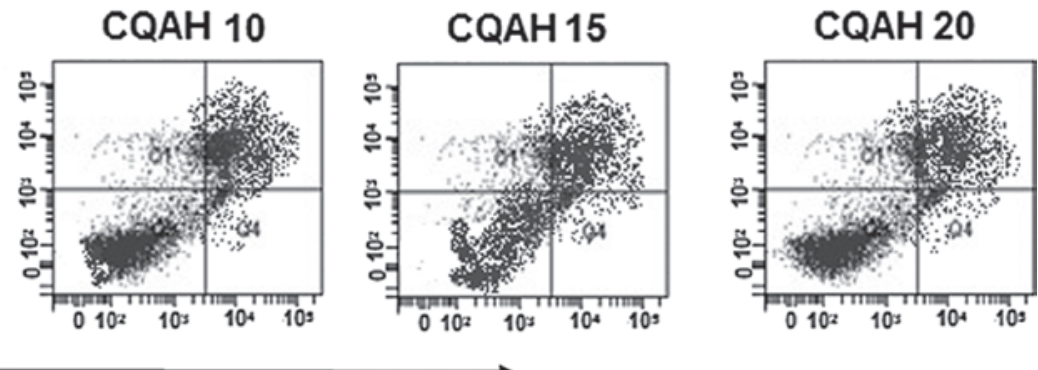

Annexin V-FITC

Figure 2. CQAH inhibits of cell growth and induces apoptosis in HCT116 and LoVo cells. (A) HCT116 and (B) LoVo cells were treated with CQAH (0-20 $\mu$ M) for 24 and $48 \mathrm{~h}$, respectively, and an MTT assay was used to assess cell viability. (C) HCT116 cells were treated with CQAH (10 $\mu \mathrm{M})$ for $48 \mathrm{~h}$ and apoptotic nuclei were identified by DAPI staining (magnification, x100). (D) Number of apoptotic nuclei and percentage of apoptotic cells determined by quantification of C. (E) Annexin-FITC/PI staining followed by flow cytometric analysis was performed to assess CQAH-induced cell death. Data were obtained from at least 3 replicates of 3 independent experiments, and are expressed as the mean \pm standard error. ${ }^{~} \mathrm{P}<0.05 ;{ }^{* *} \mathrm{P}<0.01$ vs. untreated cells. FITC, fluorescein isothiocyanate; PI, propidium iodide.

treated with CQAH for 24 or $48 \mathrm{~h}$ and subjected to MTT assays. CQAH exerted considerable cytotoxic effects on the two cell lines in a dose-dependent manner (Fig. 2A and B) with 48-h $\mathrm{IC}_{50}$-values of $\sim 10 \mu \mathrm{M}$ for HCT116 as well as LoVo. In order to assess whether CQAH can induce tumor-cell apoptosis,
HCT116 cells were treated with CQAH and morphological changes were observed by microscopy (Leica TCS SP8 STED 3X; Leica Microsystems, Wetzlar, Germany), indicating that cell shrinkage and the formation of apoptotic bodies were induced by CQAH treatment. To further verify that apoptosis 


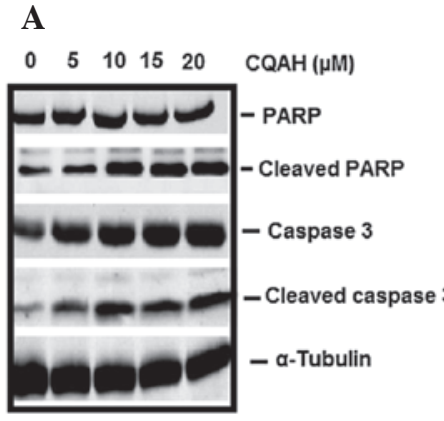

$\begin{array}{llllll}0 & 4 & 8 & 16 & 32 & \text { (h) } \mathrm{CQAH}\end{array}$

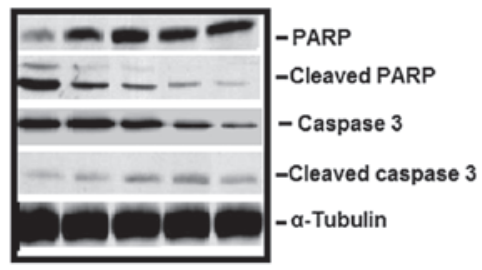

C

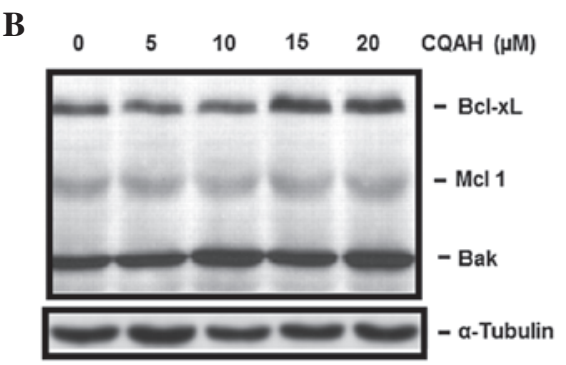

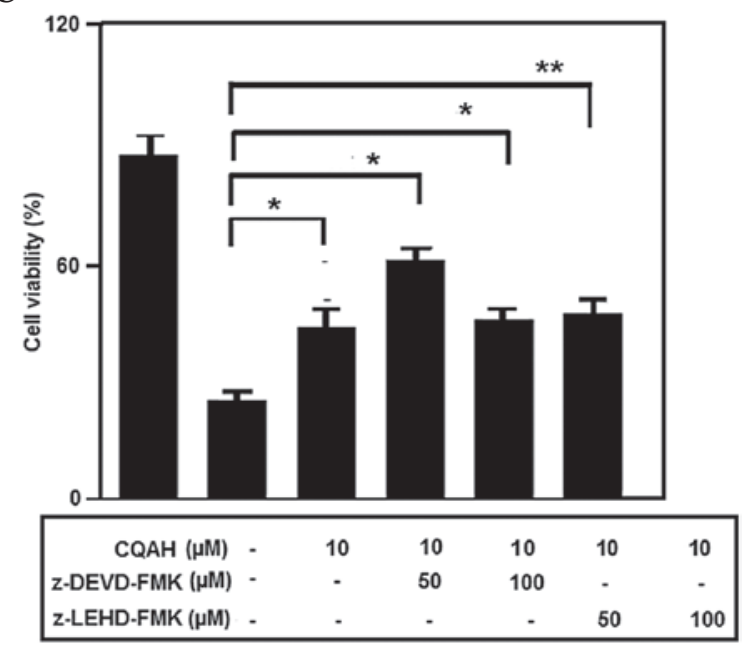

Figure 3. CQAH induces the expression of apoptotic proteins. (A) Concentration- and time-dependent induction of PARP and caspase-3 cleavage in the presence of CQAH. HCT116 cells were treated with $0-20 \mu \mathrm{M} \mathrm{CQAH}$ for $24 \mathrm{~h}$ or with $10 \mu \mathrm{M}$ CQAH for $0,4,8,16$ and $32 \mathrm{~h}$, and caspase-3 and PARP expressions were assessed using western blot analysis. $\alpha$-Tubulin was used as the loading control. (B) HCT116 cells were treated with CQAH (0-20 $\mu \mathrm{M})$ for $24 \mathrm{~h}$ and the expression of Bcl-2 family members Mcl-1, Bcl-XL and Bak was assessed using western blot analysis. (C) Cells were pre-treated with inhibitors of caspase-3 (z-DEVD-FMK; 50 and $100 \mu \mathrm{M}$ ) or caspase-9 (z-LEHD-FMK; 50 and $100 \mu \mathrm{M}$ ). CQAH $(10 \mu \mathrm{M})$ was then added for $48 \mathrm{~h}$. The cell viability was measured using an MTT assay. Data were obtained from at least three replicates of three independent experiments, and are expressed as the mean \pm standard error. ${ }^{~} \mathrm{P}<0.05 ;{ }^{* * *} \mathrm{P}<0.01$ as indicated. PARP, poly(adenosine diphosphate ribose) polymerase; Bcl-2, B-cell lymphoma 2; Bcl-XL, Bcl extra large; Bak, Bcl-2 homologous antagonist killer; Mcl, myeloid cell leukemia.

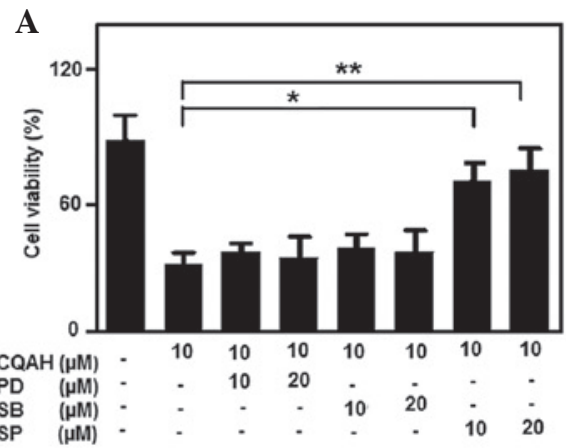

D

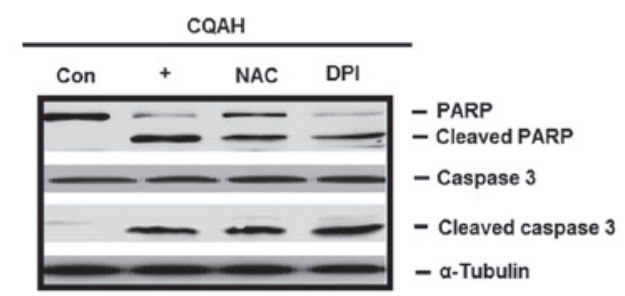

B

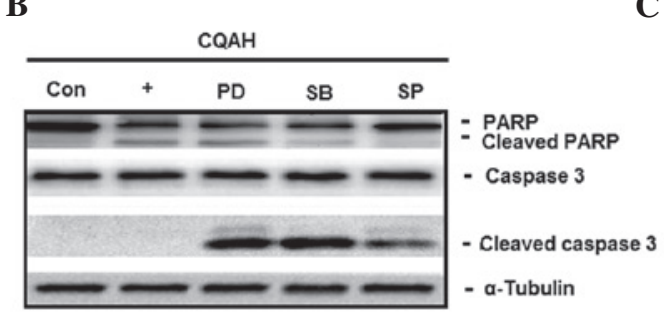

$\mathbf{E}$

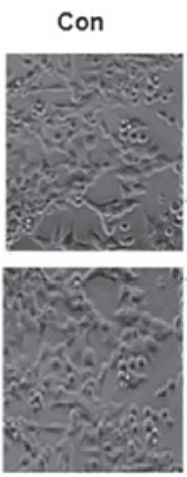

CQAH

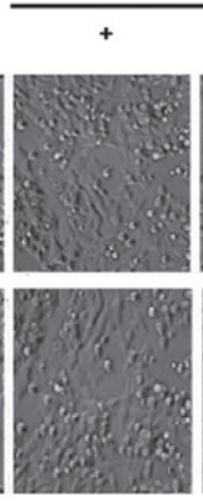

$\mathrm{PD}$
SB

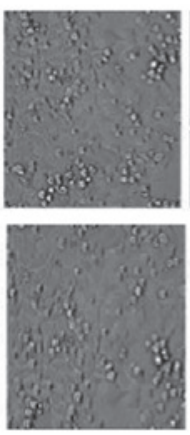

SP
C

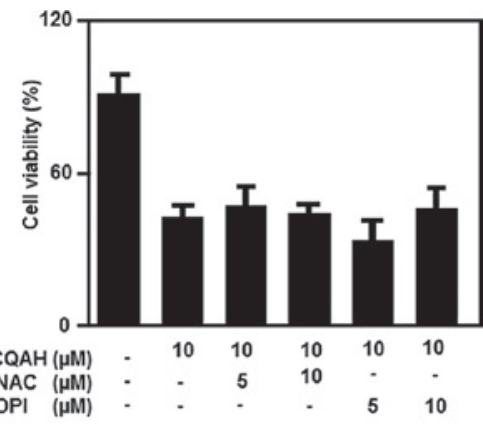

NAC

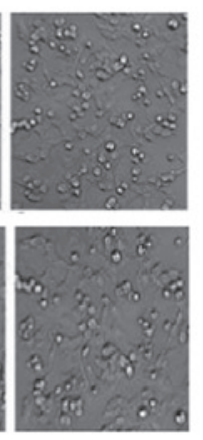

DPI

Figure 4. JNK activation-mediated CQAH induction of apoptosis, independent of reactive oxygen species involvement. (A) Cells were pre-treated with inhibitors of extracellular signal-regulated kinase (PD; 10 and $20 \mu \mathrm{M}$ ), JNK (SP; 10 and $20 \mu \mathrm{M}$ ) or p38 (SB; 10 and $20 \mu \mathrm{M}$ ). CQAH (10 $\mu \mathrm{M}$ ) treatment was performed for $48 \mathrm{~h}$ and the viability of the cells was measured using an MTT assay. (B) Cells were pre-treated with $10 \mu \mathrm{M} \mathrm{PD}$, SP or SB. CQAH (10 $\mu \mathrm{M})$ treatment was performed for $24 \mathrm{~h}$, and protein expression of PARP and caspase-3 was assessed using western blot analysis. (C) Cells were pre-treated with inhibitors of glutathione (NAC; 5 and $10 \mathrm{mM}$ ) or NADPH (DPI; 5 and $10 \mu \mathrm{M}$ ), CQAH $(10 \mu \mathrm{M})$ was added, and cells were incubated for $48 \mathrm{~h}$. The viability of the cells was assessed using an MTT assay. (D) Cells were treated with NAC $(10 \mathrm{mM})$ and DPI $(5 \mu \mathrm{M})$ in the presence of CQAH $(10 \mu \mathrm{M})$ for $24 \mathrm{~h}$, and protein expression of PARP and caspase-3 was analyzed using western blotting. (E) Bright-field images of cellular morphology were captured in the presence of the indicated inhibitors ( $20 \mu \mathrm{M}$ PD, $20 \mu \mathrm{M} \mathrm{SP}, 20 \mu \mathrm{M} \mathrm{SB}, 10 \mathrm{mM}$ NAC or $5 \mu \mathrm{M}$ DPI) and CQAH $(10 \mu \mathrm{M})$ for $48 \mathrm{~h}$ (magnification, $\mathrm{x} 100)$. Values are expressed as the mean \pm standard error. "P $<0.05 ;{ }^{* *} \mathrm{P}<0.01$ as indicated. JNK, c-Jun N-terminal kinase; PD, PD98059; SP, SP600125; SB, SB203580; NAC, N-acetyl-L-cysteine; DPI, diphenylene iodonium; Con, control; PARP, poly(adenosine diphosphate ribose) polymerase. 
was induced by CQAH, chromatin condensation was observed by staining the cells with DAPI (Fig. 2C), revealing that CQAH treatment produced a marked increase in chromatin condensation and considerably increased the amount of apoptotic nuclei from 10 to $30 \%$ (Fig. 2D). Furthermore, Annexin V-PI staining and flow cytometric analysis demonstrated an increase in the apoptotic rate from 20 to $85 \%$ upon CQAH treatment (Fig. 2E).

CQAH induces apoptosis-associated signaling in colorectal cancer cells. To examine the apoptotic pathways activated by CQAH in colorectal cancer cells, the present study assessed the effects of CQAH on two key apoptotic proteins, caspase-3 and PARP, which participate in a proteolytic signaling cascade that is activated during the apoptotic process. Western blot analysis indicated that treatment of HCT116 cells with CQAH at 0-20 $\mu \mathrm{M}$ induced apoptosis in a concentration-dependent manner by enhancing cleaved caspase-3 and PARP (Fig. 3A). Time-dependent analysis revealed that pro-caspase- 3 was reduced within $16 \mathrm{~h}$ of incubation with CQAH, whereas increased levels of cleaved caspase-3 and PARP where identified following CQAH treatment for 16-32 h (Fig. 3A). Furthermore, upon CQAH treatment, an increase in the levels of pro-apoptotic protein Bak and a decrease of anti-apoptotic proteins Bcl-XL and Mcl-1 were observed (Fig. 3B). In addition, pre-treatment with caspase-3-specific inhibitor z-DEVD-FMK and caspase-9-specific inhibitor z-LEDH-FMK significantly decreased CQAH-induced cell death (Fig. 3C).

CQAH-induced apoptosis is mediated via JNK activation. It is well known that MAPKs are broadly involved in physiological regulatory processes, which are responsible for the transduction of intracellular signaling (40). ERK, p38 and JNK have key roles in regulating cell growth and death upon MAPK activation. The present study investigated whether MAPK was involved in CQAH-induced apoptosis. For this, HCT116 cells were pre-treated with the ERK, JNK and p38 inhibitors PD98059, SP600125 and SB203580, respectively, followed by CQAH treatment. As shown in Fig. 4A, only JNK inhibition, but not p38 or ERK inhibition, significantly reduced CQAH-induced cell death. Furthermore, western blot analysis indicated that treatment with JNK inhibitor SP600125 abrogated CQAH-mediated PARP and caspase-3 cleavage (Fig. 4B), while p38 and ERK inhibitors had no marked effects. Morphological changes also confirmed that only SP600125 efficiently prevented CQAH-induced cell shrinkage and apoptotic body formation, as shown in Fig. 4E. Furthermore, intracellular oxidative stress triggered the involvement of chemopreventive product-induced cell death, which has a critical role in the activation of MAPK and hence, the present study examined the participation of reactive oxygen species (ROS) formation. As indicated in Fig. 4C, the anti-oxidant agents NAC (glutathione activator) and DPI (NAPDH inhibitor) failed to prevent CQAH-induced cell death. Similarly, the anti-oxidants failed to block the cleavage of PARP and caspase-3 (Fig. 4D) or apoptotic body formation (Fig. 4E) following treatment with CQAH. Since JNK inhibition significantly decreased CQAH-induced apoptosis, the present study further investigated the involvement of JNK by assessing JNK phosphorylation following treatment with CQAH for $4 \mathrm{~h}$ (Fig. 5A). Pre-treatment with
SP600125 reduced CQAH-mediated phosphorylation of JNK (Fig. 5B) in parallel with an elevated expression of Bcl-XL protein (Fig. 5C). In addition, the cytotoxic effects of CQAH were restored following transfection with DN-JNK (Fig. 5D), further demonstrating the involvement of the JNK pathway in CQAH-induced cytotoxicity.

CQAH enhances the therapeutic efficacy of 5-FU and CPT-11. The present study further demonstrated the synergistic effects of CQAH upon combined treatment with the pyrimidine analogue anti-colon cancer drugs 5-FU and CPT-11, which act via blocking thymidylate synthase and inhibiting topoisomerase I (41). The results clearly indicated that the cell viability was considerably reduced upon combination with 5-FU or CPT11 (Fig. 6A). Accordingly, western blot analysis showed that combined treatment of CQAH with 5-FU or CPT-11 enhanced caspase-3 and PARP cleavage (Fig. 6B). Furthermore, the present study examined the structure-activity association of two derivatives of CQAH, CQAH-1 and CQAH-2. CQAH-1 carries a methyl group at position-4 of the azetidine phenyl ring, whereas CQAH-2 carries a nitro group in the same position. Morphological observation, MTT assay and western blot analysis indicated that CQAH-1 treatment at a concentration of $20 \mu \mathrm{M}$ had a higher cytotoxic effect compared to that of CQAH, whereas CQAH-2 displayed reduced cytotoxicity (Fig. 6C-E).

\section{Discussion}

The MAPK signaling pathway regulates a variety of cellular responses with the aid of numerous intracellular and extracellular stimuli (42). The status of MAPK signaling controls cell fate, including proliferation and apoptosis. The present study demonstrated that treatment with CQAH triggered phosphorylation of JNK, whereas inhibition of JNK blocked CQAH-mediated phosphorylation of JNK as well as cleavage of caspase-3 and PARP; however, the mechanism of CQAH-mediated phosphorylation of JNK remains elusive. In spite of oxidative stress being a common trigger of cell death upstream of MAPK, participation of ROS generation was not identified following CQAH treatment, since pre-treatment with anti-oxidant agents did not affect CQAH-mediated cell death. Certain quinoline derivatives are capable of inhibiting MAPK, which activates the pro-apoptotic JNK and p38 signaling pathways (43). In a previous study, screening for potential kinase inhibitors identified a series of dihydropyrrolo pyrazole quinolines as effective potential inhibitors of the catalytic activity of MLK7 in vitro (44). A reduction in the activation of JNK and p38 with no evident effect on the activation of ERK indicated that this compound type may be suitable for blocking MLK7-mediated activation of the MAPK signaling pathway in vivo, while the underlying mechanism has remained elusive. JNK activation usually induces p53 expression, which has a major role in cell cycle regulation and activation of pro-apoptotic proteins; however, in the present study, it was observed that p53 protein levels were not altered upon CQAH treatment (data not shown), implying that CQAH-mediated apoptosis p53-independent.

Experimental results demonstrated that microtubules inhibition by paclitaxel and vincristine end up in elevation of 
A

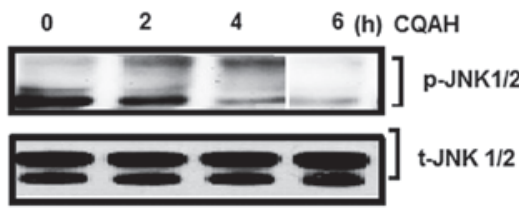

C

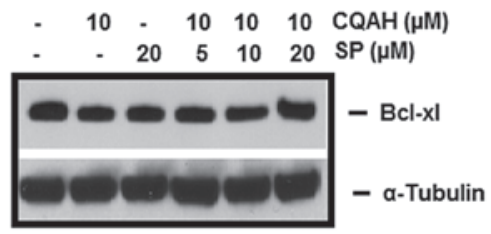

B

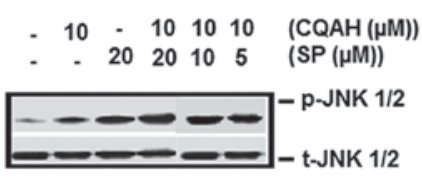

D

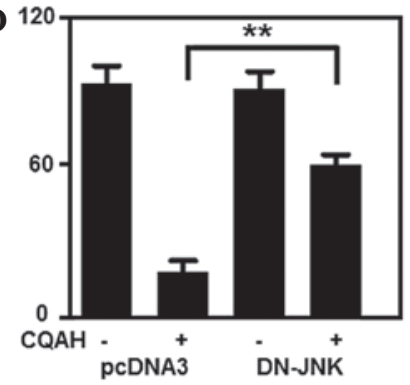

Figure 5. Activation of JNK is crucial for CQAH-induced apoptosis. (A) HCT116 cells were treated with CQAH (10 $\mu \mathrm{M})$ for 1-6 h, and phosphorylation of JNK was analyzed using western blotting. Cells were pre-treated with SP600125 $(5,10$ and $20 \mu \mathrm{M})$ and then incubated with CQAH (10 $\mu \mathrm{M})$ for $2 \mathrm{~h}$ to detect (B) p-JNK and for $24 \mathrm{~h}$ to detect (C) Mcl-1 and Bcl-XL. (D) Cells were transiently transfected with DN-JNK for $18 \mathrm{~h}$ and then treated with CQAH for $48 \mathrm{~h}$. Cell viability was measured using an MTT assay. Data were obtained from at least 3 replicates of 3 independent experiments, and are expressed as the mean \pm standard error. ${ }^{* *} \mathrm{P}<0.01$. p/t-JNK, phosphorylated/total c-Jun N-terminal kinase; Bcl-2, B-cell lymphoma 2; Bcl-XL, Bcl extra large; Bak, Bcl-2 homologous antagonist killer; Mcl, myeloid cell leukemia; SP, SP600125; DN, dominant-negative.

A

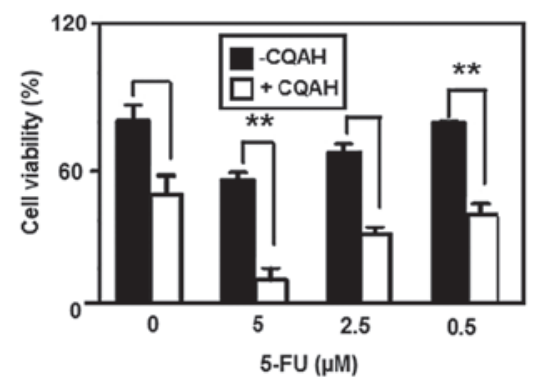

C CQAH

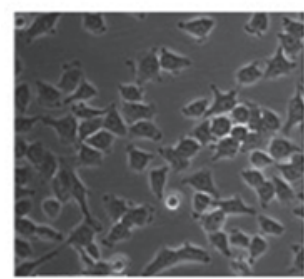

CQAH-1

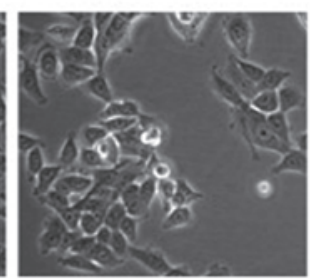

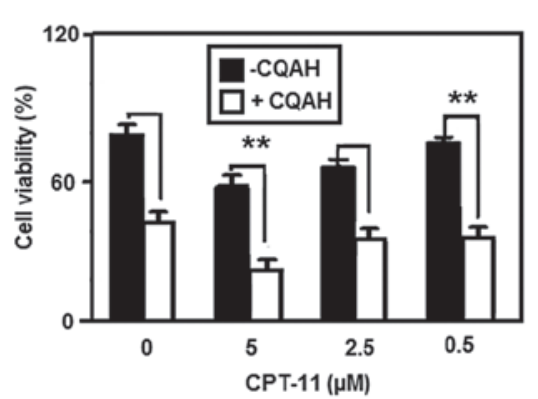

CQAH-2

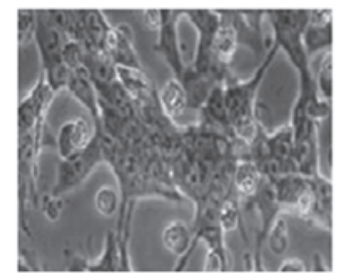

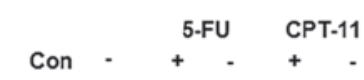

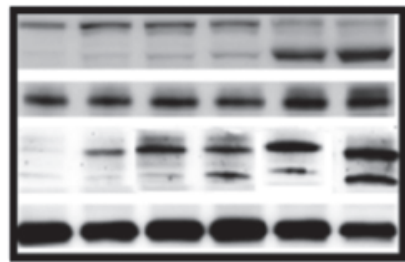

PARP

Cleaved PARP

Caspase 3

Cleaved caspase 3

a-Tubulin

$\mathbf{E}$

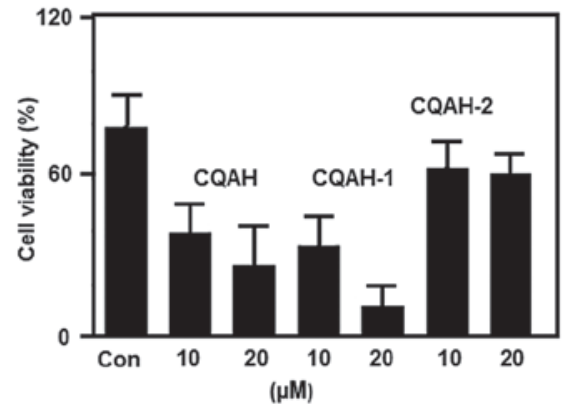

Figure 6. CQAH potentiates the therapeutic efficacy in combination with 5-FU and CPT-11, and its analogues CQAH-1 and CQAH-2 exert apoptotic effects on HCT116 cells. (A) Cells were treated with CPT-11 or 5-FU $(0,5,2.5$ or $0.5 \mu \mathrm{M})$ in the presence or absence of CQAH $(10 \mu \mathrm{M})$ for $24 \mathrm{~h}$, and cell viability was assessed using an MTT assay. (B) Cells were treated with CPT-11 or 5-FU $(5 \mu \mathrm{M})$ in the presence or absence of CQAH (10 $\mu \mathrm{M})$ for $24 \mathrm{~h}$, and caspase-3 and PARP protein expressions were analyzed using western blotting. (C) Cells were treated with CQAH, CQAH-1 or CQAH $-2(10 \mu \mathrm{M})$ for $48 \mathrm{~h}$ and the cell morphology was observed using a light microscope (magnification, x100). (D) Cells were treated with CQAH, CQAH-1 or CQAH-2 (10 or $20 \mu \mathrm{M})$ for $24 \mathrm{~h}$ and the expression of PARP and cleaved caspase-3 was analyzed using western blotting. (E) Cell viability was assessed using an MTT assay after $24 \mathrm{~h}$ of incubation. Data were obtained from at least three replicates of three independent experiments, and are expressed as the mean \pm standard error. ${ }^{* *} \mathrm{P}<0.01$. 5-FU, 5-fluorouracil; PARP, poly(adenosine diphosphate ribose) polymerase; CPT-11, camptothecin-11; Con, control. 
phosphorylation of JNK and eventually Bcl-2 phosphorylation which is also unassociated with p53 expression (45). In contrast, oxidative stress dependent apoptosis mediated through arsenite is p53 dependent and JNK independent (46). Further, JNK activation mediated apoptosis by direct phosphorylation of $\mathrm{Bcl}$ which includes Bcl-XL, Bcl-2, Bad and Bim (47-49).

ROS are involved with the upstream signaling of all members of the MAPK family. Han et al (50) reported that ROS-mediated JNK and p38 activation are necessary for sanguinarine-induced HCT116 cell death. Furthermore, Zhao et al (51) identified that JNK phosphorylation and not p38 was involved downstream of ROS signaling as part of the mechanism of olaquindox-induced apoptosis of HepG 2 cells. In the present study, ROS were not involved in CQAH-mediated apoptosis; however, JNK inhibition by SP600125 significantly reduced CQAH-induced downregulation of Bcl-XL and cell death. This finding proved that JNK-dependent $\mathrm{Bcl}$ signaling participates in CQAH-induced apoptosis. ROS are involved in various cellular functions, including cell proliferation, differentiation, necrosis and apoptosis. In addition, ROS can modify the mitochondrial permeability, which induces the loss of the mitochondrial membrane potential. As various anti-cancer drugs induce ROS-dependent mitochondrial malfunction $(52,53)$, the present study used two effective anti-oxidants, NAC and DPI, to identify whether ROS is involved in CQAH-induced cell death. However, the results showed that pre-treatment with NAC and DPI did not inhibit CQAH-mediated cell death or PARP and caspase-3 cleavage, which clearly demonstrated that neither hydrogen peroxide generation nor superoxide generation is associated with CQAH induced apoptosis and that ROS were not involved in JNK activation.

In conclusion, the results of the present study showed that substitution at position- 4 of the phenyl ring attached to azetidine affected the cytotoxicity of CQAH. As substitution at other positions or moieties may lead to further optimization of the activity of the compounds, the present study may serve as a basis for structure-based drug design of quinoline derivatives for the treatment of colon cancer. The present study identified that CQAH-induced apoptosis was mediated via JNK activation and caspases, while it was ROS-independent. Combined treatment with chemotherapeutic drugs showed that CQAH enhances their therapeutic efficacy against colon cancer. Therefore, CQAH and its derivatives are a promising class of compounds which may be developed into novel drugs for the treatment of colon cancer.

\section{Acknowledgements}

The present study was supported by the Natural Science Foundation of Liaoning Province (grant no. 2014023028) and the National Natural Science Foundation of China (grant no. 81273919).

\section{References}

1. Fearon ER and Vogelstein B: Genetic model for colorectal cancer tumorigenesis. Cell 61: 759-767, 1990.

2. Fearon ER and Jones PA: Progressing toward a molecular description of colorectal cancer development. FASEB J 6: 2783-2790, 1992.
3. Radtke F and Clevers H: Self-renewal and cancer of the gut: two sides of a coin. Science 307: 1904-1909, 2005.

4. Nelson H, Petrilli N, Carllin A, Coutoure J, Fleshman J, Guillem J, Miedema B, Ota D and Sargent D; National Cancer Institute Expert Panel: Guidelines 2000 for colon and rectal cancer surgery. J Natl Cancer Inst 93: 583-596, 2001.

5. O'Connell JB, Maggard MA and Ko CY: Colon cancer survival rates with the new American joint committee on cancer sixth edition tagging. J Natl Cancer Inst 96: 1420-1425, 2004

6. Folprecht G, Grothey A, Alberts S, Raab HR, Köhne $\mathrm{CH}$ : Neoadjuvant treatment of unresectable colorectal liver metastases: Correlation between tumour response and resection rates. Ann Oncol 16: 1311-1319, 2005.

7. Edwards MS, Chadda SD, Zhao Z, Barber BL and Sykes DP: A systematic review of treatment guidelines for metastatic colorectal cancer. Colorectal Dis 14: e31-e47, 2012.

8. Thun MJ, Namboodiri MM and Heath CW Jr: Aspirin use and reduced risk of fatal colon cancer. N Engl J Med 325: 1593-1596, 1991.

9. Thun MJ, Namboodiri MM, Calle EE, Flanders WD and Heath CW Jr: Aspirin use and risk of fatal cancer. Cancer Res 53: 1322-1327, 1993.

10. Marnett LJ: Aspirin and the potential role of prostaglandins in colon cancer. Cancer Res 52: 5575-5589, 1992.

11. Marnett LJ: Aspirin and related nonsteroidal anti-inflammatory drugs as chemopreventive agents against colon cancer. Prev Med 24: 103-106, 1995.

12. Giovannucci E, Rimm EB, Stampfer MJ, Colditz GA, Ascherio A and Willett WC: Aspirin use and the risk for colorectal cancer and adenoma in male health professionals. Ann Intern Med 121: 241-246, 1994.

13. Giovannucci E, Egan KM, Hunter DJ, Stampfer MJ, Colditz GA, Willett WC and Speizer FE: Aspirin and the risk of colorectal cancer in women. N Engl J Med 333: 609-614, 1995.

14. Waddell WR and Loughry RW: Sulindac for polyposis of the colon. J Surg Oncol 24: 83-87, 1983.

15. Waddell WR, Ganser GF, Cerise EJ and Loughry RW: Sulindac for polyposis of the colon. Am J Surg 157: 175-179, 1989.

16. Giardiello FM, Hamilton SR, Krush AJ, Piantadosi S, Hylind M, Celano P, Booker SV, Robinson CR and Offerhaus GJ: Treatment of colonic and rectal adenomas with sulindac in familial adenomatous polyposis. N Engl J Med 328: 1313-1316, 1993.

17. Giardiello FM, Offerhaus GJ and DuBois RN: The role of nonsteroidal anti-inflammatory drugs in colorectal cancer prevention. Eur J Cancer 31A: 1071-1076, 1995.

18. Hare JI, Neijzen RW, Anantha M, Dos Santos N, Harasym N, Webb MS, Allen TM, Bally MB and Waterhouse DN: Treatment of colorectal cancer using a combination of liposomal irinotecan (Irinophore $\mathrm{C}^{\mathrm{TM}}$ ) and 5-fluorouracil. PLoS One 8: e62349, 2013.

19. Allen WL, Coyle VM, Jithesh PV, Proutski I, Stevenson L, Fenning C, Longley DB, Wilson RH, Gordon M, Lenz HJ and Johnston PG: Clinical determinants of response to irinotecan-based therapy derived from cell line models. Clin Cancer Res 14: 6647-6655, 2008.

20. Troiani T, Serkova NJ, Gustafson DL, Henthorn TK, Lockerbie O, Merz A, Long M, Morrow M, Ciardiello F and Eckhardt SG: Investigation of two dosing schedules of vandetanib, ZD6474, an inhibitor of vascular endothelial growth factor receptor and epidermal growth factor receptor signaling, in combination with irinotecan in a human colon cancer xenograft model. Clin Cancer Res 13: 6450-6458, 2007.

21. Pancreach E, Guérin E, Nicolet C, Lelong-Rebel I, Voegeli AC, Oudet P, Larsen AK, Gaub MP and Guenot D: Marked activity of irnotecan and rapamycin combination toward colon cancer cells in vivo and in vitro is mediated through cooperative modulation of the mammalian target of rapamycin/hypoxia inducible factor-1apha axis. Clin Cancer Res 15: 1297-1307, 2009.

22. Chen YL, Lin PC, Chen SP, Lin CC, Tsai NM, Cheng YL, Chang WL, Lin SZ and Harn HJ: Activation of nonsteroidal anti-inflammatory drug-activated gene-1 via extracellular signal-regulated kinase $1 / 2$ mitogen-activated protein kinase revealed a isochaihulactone-triggered apoptotic pathway in human lung cancer A549 cells. J Pharmacol Exp Ther 323: 746-756, 2007.

23. Egan TJ: Interactions of quinoline antimalarials with hematin in solution. J Inorg Biochem 100: 916-926, 2006.

24. Abonia R, Insuasty D, Castillo J, Insuasty B, Quiroga J, Nogueras $\mathrm{M}$ and Cobo J: Synthesis of novel quinoline-2-one based chalcones of potential anti-tumor activity. Eur J Med Chem 57: 29-40, 2012 
25. Dürckheimer W, Blumbach J, Lattrell R and Scheunemann KH: Recent developments in the field of $\beta$-Lactam antibiotics. Angew Chem Int Ed Engl 24: 180-202, 1985.

26. Khalafallah AK, Selim MA, El-Hamd RMA, Elmaghraby MA, Soleiman et al: Novel synthesis of some new fused/spiro heterocyclic compounds and their biological activity. Indian J Chem 34, 1066-1070, 1995.

27. Parikh KA, Oza PS and Parikh AR: Synthesis of some new 2-azetidinones as potential antitubercular agents. Indian J Chem 39B: 716, 2000.

28. Patel NB and Patel JC: Synthesis and antimicrobial activity of Schiff bases and 2-azetidinones derived from quinazolin-4(3H)-one. Arabian J Chem 4: 403-411, 2011.

29. Parmar SJ and Patel JI: Synthesis and biological evaluation of some novel optically active3-chloro-1-[4-(\{4-[(S)-(4-chlorophenyl) (phenyl)methyl]-1-piperazinyl\}acetyl)phenyl]-4-aryl-2-azetidinonederivatives. Der Pharma Chemica 2: 141-151, 2010.

30. Mathew B, Elizebeth MG, Mathew N and Vijayabaskaran M: Synthesis, Characterisation of some 2-azetidinone derivatives from 2-aminopyridine and evaluation of their antimicrobial activity. Der Pharma Chemica 6: 238-242, 2012.

31. Vashi BS,MehtaDS and Shah VH:Synthesis and biological activity of 4-thiazolidinones, 2-azetidinones, 4-imidazolinone derivatives having thymol moiety. Indian J Chem 34B: 802-808, 1995.

32. Polanski J, Niedbala H, Musiol R, Podeszwa B, Tabak D, et al: 5-Hydroxy-8-nitro-6-quinaldic acid as a novel molecular scaffold for HIV-1 integrase inhibitors. Lett Drugs Des Disc 3 . 175-178, 2006.

33. Polanski J, Niedbala H, Musiol R, Podeszwa B, Tabak D, et al: Fragment based approach for the investigation of HIV-1 integrase inhibition. Lett Drugs Des Disc 4: 99-105, 2007.

34. Musiol R, Tabak D, Niedbala H, Podeszwa B, Jampilek J, Kralova K, Dohnal J, Finster J, Mencel A and Polanski J: Investigating biological activity spectrum for novel quinolineanalogues 2: Hydroxyquinolinecarboxamides with photosynthesis inhibiting activity. J Bioorg Med Chem 16: 4490-4499, 2008

35. Jampilek J, Musiol R, Pesko M, Kralova K, Vejsova M, Carroll J, Coffey A, Finster J, Tabak D, Niedbala H, et al: Ring-substituted 4-Hydroxy-1H-quinolin-2-ones: Preparation and biological activity. J Molecules 14: 1145-1159, 2009.

36. Patel R, Kumari P and Chikhalia K: Novel s-Triazinyl piperazines: Design, synthesis, characterization and anti-microbial activity. Archives of Applied Science Research 6: 232-240, 2010

37. Mistry B and Jauhari S: Synthesis and characterization of some quinoline based azetidinones and thiazolidinones as antimicrobial agents. Archives of Applied Science Research 6: 332-343, 2010.

38. Parmar SJ and Patel IJ: Synthesis and biological evaluation of some novel optically active3-chloro-1-[4-(\{4-[(S)-(4-chlorophenyl) (phenyl)methyl]-1-piperazinyl\}acetyl)phenyl]-4-aryl-2-azetidinonederivatives. Der Pharma Chemica 1: 141-151, 2010.

39. Madhu G, Jayaveera KN, Ravindra Nath LK, Kumar BS and Nagarjuna Reddy P: Synthesis and structure activity relationship of new antibacterial active multi substituted quinoline-azetidone mannich bases. Der Pharma Chemica 3: 1033-1040, 2012

40. Johnson GL and Lapadat R: Mitogen-activated protein kinase pathways mediated by ERK, JNK, and p38 protein kinases. Science 298: 1911-1912, 2002.
41. Ishihara Y, Matsunaga K, Iijima H, Hasegawa G, Suzuki T, Sato A, Kobayashi T, Yang M and Hoffman RM: The combination of 5-FU, leucovorin and CPT-11 (FOLFIRI) prolongs survival through inhibition of metastasis in an orthotopic model of colon cancer. Anticancer Res 30: 403-408, 2010.

42. Zhang W and Liu HT: MAPK signal pathways in the regulation of cell proliferation in mammalian cells. Cell Res 12: 9-18, 2002

43. Olsson H, Sjö P, Ersoy O, Kristoffersson A, Larsson J and Nordén B: 4-Anilino-6-phenyl-quinoline inhibitors of mitogen activated protein kinase-activated protein kinase 2 (MK2). Bioorg Med Chem Lett 20: 4738-4740, 2010.

44. Wang X, Mader MM, Toth JE, Yu X, Jin N, Campbell RM, Smallwood JK, Christe ME, Chatterjee A, Goodson T Jr, et al: Complete inhibition of anisomycin and UV radiation but not cytokine induced JNK and p38 activation by an aryl-substituted hydropyrrolopyrazole quinoline and mixed lineage kinase 7 small interfering RNA. J Biol Chem 280: 19298-19305, 2005.

45. Zhu BK, Wang $\mathrm{P}$, Zhang XD, Jiang CC, Chen LH, Avery-Kiejda KA, Watts R and Hersey P: Activation of Jun $\mathrm{N}$-terminal kinase is a mediator of vincristine-induced apoptosis of melanoma cells. Anticancer Drugs 19: 189-200, 2008.

46. Muscarella DE and Bloom SE: The contribution of c-Jun $\mathrm{N}$-terminal kinase activation and subsequent Bcl-2 phosphorylation to apoptosis induction in human B-cells is dependent on the mode of action of specific stresses. Toxicol Appl Pharmacol 228: 93-104, 2008.

47. Kelkel M,Cerella C,MackF, SchneiderT, Jacob C, Schumacher M, Diederich $\mathrm{M}$ and Diederich M: ROS-independent JNK activation and multisite phosphorylation of Bcl-2 link diallyl tetrasulfide-induced mitotic arrest to apoptosis. Carcinogenesis 33: 2162-2171, 2012

48. Leung KT, Li KK, Sun SS, Chan PK, Ooi VE and Chiu LC: Activation of JNK pathway promotes phosphorylation and degradation of BimEL-a novel mechanism of chemoresistance in T-cell acute lymphoblastic leukemia. Carcinogenesis 29: 544-551, 2008

49. Donovan N, Becker EB, Konishi Y and Bonni A: JNK phosphorylation and activation of BAD couples the stress-activated signaling pathway to the cell death machinery. J Biol Chem 277: 40944-40949, 2002

50. Han MH, Kim GY, Yoo YH and Choi YH: Sanguinarine induces apoptosis in human colorectal cancer HCT-116 cells through ROS-mediated Egr-1 activation and mitochondrial dysfunction. Toxicol Lett 220: 157-166, 2013.

51. Zhao WX, Tang SS, Jin X et al: Olaquindox-induced apoptosis is suppressed through p38 MAPK and ROS-mediated JNK pathways in HepG2 cells. Cell Biol Toxicol 29: 229-238, 2013.

52. Kuo YF, Su YZ, Tseng YH, Wang SY, Wang HM and Chueh PJ: Flavokawain B, a novel chalcone from Alpinia pricei Hayata with potent apoptotic activity: Involvement of ROS and GADD153 upstream of mitochondria-dependent apoptosis in HCT116 cells. Free Radic Biol Med 49: 214-226, 2010.

53. Quan Z, Gu J, Dong P, Lu J, Wu X, Wu W, Fei X, Li S, Wang Y, Wang J and Liu Y: Reactive oxygen species-mediated endoplasmic reticulum stress and mitochondrial dysfunction contribute to cirsimaritin-induced apoptosis in human gallbladder carcinoma GBC-SD cells. Cancer Lett 295: 252-259, 2010. 